\title{
Environmental Health Studies in the Korean National Industrial Complexes (EHSNIC): Focus-Group Interviews
}

\author{
Ji Ae $\operatorname{Lim}^{1} \odot$, Ho-Jang Kwon ${ }^{1}$, Hyun-Joo Kim², Mina Ha ${ }^{1}$, Xue Han ${ }^{1}$, \\ 'Department of Preventive Medicine, Dankook University College of Medicine, Cheonan, Korea; ${ }^{2}$ Department of Occupational and Environmental \\ Medicine, Ewha Womans University College of Medicine, Seoul, Korea
}

\begin{abstract}
This study investigated the social outcomes of the Environmental Health Studies of National Industrial Complex (EHSNIC), which have been conducted by the National Institute of Environmental Research (NIER) in eight National Industrial Complex Areas (NICAs) since 2003. Eighteen sessions of focus-group interviews with 85 people were conducted from October 2016 to January 2017. Interviewees were stakeholders from eight NICAs and included resident representatives, environmental nongovernment organizations, local government officials, and environmental health and safety officers from companies. Interview results were divided into six categories: EHSNIC awareness, EHSNIC outcomes, EHSNIC limitations, EHSNIC continuation, EHSNIC improvement directions, and EHSNIC results use. They were then further indexed into 23 divisions. EHSNIC awareness varied across stakeholders. A major EHSNIC outcome is that a continued result database was established, which was used as a reference for environmental improvements. EHSNIC limitations included no proper healthcare actions taken during the EHSNIC study period, a lack of EHSNIC results disclosure, a failure to reflect local specificity, and a lack of validity in the results. Regarding EHSNIC continuation, all stakeholders said EHSNIC should be conducted continuously. EHSNIC improvement directions included conducting studies tailored to each NICA, identifying correlations between pollutant exposure and disease, increasing the sample size, and performing repeated studies. Regarding EHSNIC results use, respondents wanted to use the results as a reference to relocate residents, ensure distance between NICAs and residential areas, provide healthcare support, develop local government policies, and implement firms' environmental controls. Since EHSNIC aims to identify the health effects of NICAs on residents and take appropriate actions, it should be continued in the future. Even during the study period, it is important to take steps to preventively protect residents' health. EHSNIC also needs to reflect each NICA's characteristics and conduct reliable research based on stakeholder participation and communication.
\end{abstract}

Keywords: National Industrial Complex Areas, Environmental Health Study, qualitative research, focus-group interview, stakeholder

\section{INTRODUCTION}

National Industrial Complex Areas (NICAs) are key infrastructures in Korea's economic development [1]. In the 1960s, the Korean government established the 1st Five-Year Economic Development Plan (1962-1966) to rapidly grow its underdeveloped economy. It built the Ulsan NICA in 1962 and the Korean Export NICA in 1964 to put in place export-led heavy-industry-first policies. The number of NICAs continued to rise until the 1980s, stagnating a bit during the 1990s and then rising again in the 2000s [2]. As of the first half of 2017, 1,161

Received: Oct 25, 2017 Accepted: Feb 10, 2019

Corresponding author: Hyun-Joo Kim

52 Ewhayeodae-gil, Seodaemun-gu, Seoul 03760, Korea

E-mail: hyunjoo@ewha.ac.kr

Funding: This study was supported by the National Institute of Environmental

Research, Republic of Korea (NIER-SP2016-295).

This article is available from: http://e-eht.org/
NICAs have been established, housing 93,337 companies and employing 2.15 million people [3].

As large-scale production facilities have been densely built in NICAs and have gradually expanded their scale, they have moved close to residential areas, creating problems of exposure to environmental pollution $[4,5]$ and its subsequent health effects on residents [6, 7]. Examples include the Onsan Illness in the 1980s, in which more than 500 residents adjacent to the Onsan NICA reported nonspecific pain in their skin, musculoskeletal system, eyes, nervous system, and respiratory system [8]. There was also a contamination of drinking water supplies with phenol in 1991, in which 30 tons of phenol from the Gumi NICA were leaked into the water source; residents reported nausea, vomiting, diarrhea, abdominal pain, headaches, irritation in the mouth and throat, and skin symptoms [9]. Further, there was the glass fiber landfill accident at Gojandong, Incheon, in 1995, in which 700 tons of waste, including 
glass fibers buried near the factory, contaminated drinking water (underground water) and caused a lipoma [10]. In addition, there were the Gumi hydrofluoric acid leak of 2012 and the Cheongju hydrofluoric acid leak of 2013, which caused damage to people and the environment [11]. The National Institute of Environmental Research (NIER) has conducted the Environmental Health Studies of National Industrial Complex Areas (EHSNIC) on eight large NICAs (Yeosu, Gwangyang, Pohang, Sihwa, Banwol, Ulsan, Cheongju, and Daesan) to assess exposure to hazardous substance and health effects on residents and prevent health damage [6]. The first EHSNIC phase (2003-2010) was a cohort study, and the second (20122015) was a cross-sectional study. Major details of the EHSNIC included environmental pollution assessment using atmospheric monitoring network data, resident health status surveys from health screenings (first phase only), questionnaire surveys (first and second phases), and pollutant exposure level surveys for heavy metals (lead, cadmium, and mercury), volatile organic compounds (VOCs), and polycyclic aromatic hydrocarbons (PAHs) [6, 12].

The present research is a qualitative study based on focusgroup interviews (FGI). It was conducted to analyze the EHSNIC's social outcomes as part of the Evaluation of EHSNIC, which was performed in 2016 to assess the second phase of EHSNIC. In addition to the results obtained from the analysis of the EHSNIC, its social outcomes in this study included the subjective evaluations of stakeholders, which were divided into EHSNIC awareness, outcomes, limitations, continuation, improvement directions, and results use.

In qualitative research, interviewees can talk freely through the use of semi-structured interview questionnaires; this approach can provide an in-depth understanding of a particular area of research interest. Since qualitative research focuses on understanding and interpreting a certain situation or phenomenon, it is useful for exploring a social phenomenon and interpreting a complex situation [13]. The FGI is one method in qualitative research, and it is conducted on a small homogenous group of respondents (6-12 on average).

In what follows, we provide the results of FGIs conducted with stakeholders connected to eight NICAs in five regions. They included resident representatives, environmental nongovernment organizations (enviro-NGOs), local government officials, and environmental health and safety (EHS) officers from companies. These findings shed light on social outcomes in the areas where EHSNIC has been conducted.

\section{METHODS}

\section{Select Focus-Group Interviewees}

Focus-group interviewees were selected from resident representatives, enviro-NGOs, local government officials, and EHS officers from companies in eight NICAs and five regions where EHSNIC has been conducted. Resident representatives included chiefs in neighborhoods or villages who participate in EHSNIC or members of the Regional development council, among other residential areas closely adjacent to NICAs. Enviro-NGOs included working-level officers in regions that conduct environmental improvement activities for their NICA. Local government officials were working-level managers in charge of the EHSNIC in local governments; EHS officers were

Table 1. Content of the semi-structured interview questionnaire about the National Industrial Complex Area (NICA) and the Environmental Health Study of National Industrial Complex (EHSNIC)

\begin{tabular}{|c|c|}
\hline Category & Content \\
\hline NICA awareness & $\begin{array}{l}\text { Q. What do you think about the NICA in your region? } \\
\text { Q. What do you think of the environmental control of the NICA compared to in the past? } \\
\text { Q. Has your company's environmental control cost changed? Budget scale, or items? (EHS officer only) } \\
\text { Q. Do you think there has been any change in NICA-related civil complaints compared to the past? If so, what kind of change do you think has } \\
\text { occurred? (local government official only) }\end{array}$ \\
\hline EHSNIC comments & $\begin{array}{l}\text { Q. Are you aware of the EHSNIC conducted by the Ministry of Environment? } \\
\text { Q. Do you think the EHSNIC has delivered any outcome? If so, what do you think it is? } \\
\text { Q. Do you think the EHSNIC helps to improve the environment? } \\
\text { Q. What do you think are the EHSNIC's problems or areas it needs to improve, if any? } \\
\text { Q. Do you think the EHSNIC should continue? } \\
\text { Q. How do you want the EHSNIC results to be used? } \\
\text { Q. Has there been any case where your company changed its environmental control policy, requirements, or budget based on EHSNIC results? } \\
\text { (EHS officer only) }\end{array}$ \\
\hline Communication & $\begin{array}{l}\text { Q. Is there any project that your company supports for residents in the NICA? (EHS officer only) } \\
\text { Q. Do you have anything to say to local governments or companies in relation to the NICA? (resident representative only) } \\
\text { Q. What do you think would be good to be provided to residents in the NICA? (resident representative and environ-NGO only) } \\
\text { Q. Is there anything that would be good to be supported by connecting the EHSNIC with your local government? (local government official only) } \\
\text { Q. Have you used the EHSNIC results for your work or to communicate with residents? (local government official only) }\end{array}$ \\
\hline
\end{tabular}

*EHS officer: environmental health and safety officers, enviro-NGOs: environmental nongovernment organizations. 
included from large companies (300 employees or more) and small ones (20-300 employees) in NICAs. They were recruited from the government point of contact or the business council.

\section{Develop and Send the Interview Questionnaire}

The interview questionnaire was developed by identifying the results of the first and second phases of the EHSNIC and major issues in NICAs, as well as referencing previous studies in Korea and abroad (Table 1). The content of the questionnaire largely consisted of NICA awareness, EHSNIC comments, and communication via common questions as well as questions specific to different stakeholders. Questionnaires were provided, along with an EHSNIC overview (two pages), to interviewees via post or e-mail before the FGIs.

\section{Conduct Interviews}

FGIs were conducted in groups for resident representatives and EHS officers by individual NICA or region, and for local government officials and enviro-NGOs together in NICAs. Individual interviews were conducted with those who did not attend the group interviews. The interviews took 1.5-2.0 hours, and 5-6 individuals attended them on average. Before the interviews began, we obtained consent to record the interviews; interviewees then filled out a consent form to allow us to identify their personal information. After the EHSNIC overview was explained, the interviews were conducted in a way that allowed the interviewees to talk freely following the interviewer's questions.

\section{Data Anallysis and Interpretation}

This study was based on grounded theory, among other qualitative research methods. Data were analyzed following McCracken's method. First, recorded interview data were transcribed verbatim by a professional stenographer without any summarizing or excerpting. Second, we read the transcripts and disassembled them by contexts and terms. Third, to understand the qualitative data's context, we reviewed previous

Table 2. Progress results of focus-group interviews (FGl) $(n=16)$

\begin{tabular}{llc}
\hline & \multicolumn{1}{c}{ Variables } & Number of interviews (\%) \\
\hline Stakeholders & Resident representative & $6(33.3)$ \\
& Enviro-NGO & $4(22.2)$ \\
& EHS officer & $2(11.1)$ \\
Size & Local government official & $6(33.3)$ \\
& Group & $16(88.8)$ \\
Participation region & Individual & $2(11.2)$ \\
& A region & $16(88.8)$ \\
& All regions & $2(11.2)$
\end{tabular}

*EHS officer: environmental health and safety officers, enviro-NGOs: environmental nongovernment organizations.
NICA-related studies in Korea and abroad, the Ministry of Environment's EHSNIC results and evaluation reports, and environmental and health effects data for each NICA from EHSNIC's first and second phases. Then, the data were reassembled based on logical relations such as content repeatability, similarity, and inconsistency. Fourth, the qualitative data were classified, categorized, and systemized by topic. Fifth, we examined how content divided by topic was integrated and suggested interpretations and conclusions for key issues. While this five-step process was conducted consecutively, each step was performed in a circular and repeated way $[13,14]$.

\section{Results}

\section{Study Participants}

FGIs were conducted over the course of 18 sessions from October 2016 to January 2017, including six for resident representatives, four for enviro-NGOs, two for local government officials, and six for EHS officers (total participants: 85). Group interviews were conducted in 16 of the 18 sessions; individual interviews were conducted for enviro-NGOs and local government officials. As for gender, there were 65 men $(76.5 \%)$ and 20 women $(23.5 \%)$. Thirty-three resident representatives (33.8\%), nine enviro-NGOs (10.6\%), 38 EHS officers (44.7\%), and five local government officials (5.88\%) participated in the FGIs (Tables 2 and 3 ).

\section{Categorical Indexing and Analysis Results}

The transcripts were deconstructed and indexed into six categories that could identify EHSNIC social outcomes: EHSNIC awareness, EHSNIC outcomes, EHSNIC limitations, EHSNIC continuation, EHSNIC improvement directions, and EHSNIC results use. Details of the six categories were further split into 23 divisions (Table 4). Table 5. shows the distribution of com-

Table 3. Sociodemographic characteristics of the interviewees $(n=85)$

\begin{tabular}{llc}
\hline & \multicolumn{1}{c}{ Variables } & Number of interviewees (\%) \\
\hline Sex & Male & $65(76.5)$ \\
Stakeholders & Female & $20(23.5)$ \\
& Resident representative & $33(38.8)$ \\
& Enviro-NGO & $9(10.6)$ \\
National & EHS officer & $38(44.7)$ \\
Industrial & Local government official & $5(5.88)$ \\
Complex & Gwangyang & $15(17.6)$ \\
Areas (NICAs) & Yeosu & $13(15.3)$ \\
& Pohang & $17(20.0)$ \\
& Sihwa and Banwol & $13(15.3)$ \\
& Ulsan & $17(20.0)$ \\
& Cheongju and Daesan & $10(11.8)$
\end{tabular}

*EHS officer: environmental health and safety officers, enviro-NGOs: environmental nongovernment organizations 
Table 4. Categorical indexing of focus-grouped interview (FGl) results about the National Industrial Complex Area (NICA) and the Environmental Health Study of National Industrial Complex (EHSNIC)

\begin{tabular}{|c|c|c|}
\hline Category & Division & Section \\
\hline EHSNIC awareness & EHSNIC awareness & Participation, monitoring, lack of awareness, administrative support \\
\hline EHSNIC outcomes & $\begin{array}{l}\text { Persistence } \\
\text { Database establishment } \\
\text { Environment improvement }\end{array}$ & $\begin{array}{l}\text { Conducted long term, every year } \\
\text { Establish a national database } \\
\text { Provide reference data to improve the environment }\end{array}$ \\
\hline EHSNIC limitation & $\begin{array}{l}\text { No healthcare action taken based on the results } \\
\text { Lack of results release } \\
\text { Survey design not reflecting local characteristics } \\
\text { Validity for the EHSNIC and its results }\end{array}$ & $\begin{array}{l}\text { Environmental improvements, follow-up actions for the health effect } \\
\text { Not notify the subjects of their results, lack of disclosure for the results } \\
\text { Survey item suitable for the NICA } \\
\text { Consider NICA beginning background, results, measurement points, subjects, } \\
\text { compounding variables }\end{array}$ \\
\hline EHSNIC continuation & Necessity & Need to continue, NICA subjects \\
\hline EHSNIC improvement directions & $\begin{array}{l}\text { Reflect NICA specificity } \\
\text { Identify pollutant exposure's correlation with disease } \\
\text { Expand survey subjects and ensure representation } \\
\text { Include long-term residents } \\
\text { Repeated study } \\
\text { Long-term study } \\
\text { Include health screening and cancer screening } \\
\text { Results release } \\
\text { Reliability }\end{array}$ & $\begin{array}{l}\text { Reflect specific pollutants (VOCs), climate conditions } \\
\text { (wind direction, atmospheric pressure) } \\
\text { Causality, level of contribution } \\
\text { Sample size, include children } \\
\text { Resident history } \\
\text { Repeated studies on the same subjects to identify causality between exposure } \\
\text { and health } \\
\text { Improve the results' accuracy } \\
\text { Health and cancer screening tailored to the NICA } \\
\text { Scope of disclosure } \\
\text { Survey institution, communication, participation and support from residents and } \\
\text { enviro-NGOs }\end{array}$ \\
\hline EHSNIC results use & $\begin{array}{l}\text { Resident relocation } \\
\text { Separation distance } \\
\text { Healthcare for residents } \\
\text { Local government policy development } \\
\text { Environmental control guidelines for companies }\end{array}$ & $\begin{array}{l}\text { Residents closely adjacent to the NICA, residents in complex pollution areas } \\
\text { Greenbelt } \\
\text { Healthcare support, healthcare cost support } \\
\text { Reference for local government policy, or special local act } \\
\text { Company's own guidelines, consultation, technical support }\end{array}$ \\
\hline
\end{tabular}

Table 5. Distribution of focus-grouped interview (FGI) results by stakeholders about about the National Industrial Complex Area (NICA) and the Environmental Health Study of National Industrial Complex (EHSNIC)

\begin{tabular}{|c|c|c|c|c|c|}
\hline & \multirow[b]{2}{*}{ Category } & \multicolumn{4}{|c|}{ Stakeholders } \\
\hline & & $\begin{array}{c}\text { Resident } \\
\text { representatives }\end{array}$ & Enviro-NGOs & $\begin{array}{l}\text { Local government } \\
\text { officials }\end{array}$ & $\begin{array}{c}\text { EHS officers from } \\
\text { companies }\end{array}$ \\
\hline Awareness & Awareness of EHSNIC & 0 & O & $\triangle$ & $\triangle$ \\
\hline Outcomes & $\begin{array}{l}\text { Persistence } \\
\text { Construction of database } \\
\text { Environment improvement }\end{array}$ & $\begin{array}{l}- \\
0 \\
0\end{array}$ & $\begin{array}{l}- \\
-\end{array}$ & $\begin{array}{l}0 \\
0 \\
0\end{array}$ & $\begin{array}{l}0 \\
0 \\
0\end{array}$ \\
\hline Limitations & $\begin{array}{l}\text { No healthcare action taken based on the results } \\
\text { Lack of results release } \\
\text { Survey design not reflecting local characteristics } \\
\text { Validity for the EHSNIC and its results }\end{array}$ & $\begin{array}{l}0 \\
0 \\
0 \\
0\end{array}$ & $\begin{array}{l}\bigcirc \\
0 \\
0 \\
0\end{array}$ & $\begin{array}{l}- \\
0 \\
0\end{array}$ & $\begin{array}{l}- \\
0 \\
0\end{array}$ \\
\hline Continuation & Necessity & 0 & 0 & 0 & 0 \\
\hline Improvement directions & $\begin{array}{l}\text { Reflect the NICA specificity } \\
\text { Identify pollutant exposure's correlation with disease } \\
\text { Expand survey subjects, ensure representation } \\
\text { Include long-term residents } \\
\text { Repeated study } \\
\text { Long-term study } \\
\text { Include health screening and cancer screening } \\
\text { Results release } \\
\text { Reliability }\end{array}$ & $\begin{array}{l}0 \\
0 \\
0 \\
0 \\
0 \\
- \\
0 \\
0 \\
0\end{array}$ & $\begin{array}{l}0 \\
0 \\
0 \\
0 \\
0 \\
- \\
0 \\
0 \\
0\end{array}$ & $\begin{array}{l}0 \\
- \\
- \\
0 \\
0 \\
0 \\
- \\
\triangle \\
0\end{array}$ & $\begin{array}{l}0 \\
- \\
- \\
0 \\
0 \\
0 \\
- \\
\triangle \\
0\end{array}$ \\
\hline Results use & $\begin{array}{l}\text { Resident relocation } \\
\text { Separation distance } \\
\text { Healthcare for residents } \\
\text { Local government policy development } \\
\text { Environmental control guidelines for companies }\end{array}$ & $\begin{array}{l}0 \\
0 \\
0 \\
- \\
-\end{array}$ & $\begin{array}{l}0 \\
0 \\
0 \\
0\end{array}$ & $\begin{array}{l}- \\
0 \\
0 \\
0\end{array}$ & $\begin{array}{l}\triangle \\
\triangle \\
- \\
0 \\
0\end{array}$ \\
\hline
\end{tabular}

$\mathrm{O}$ : majority opinion; $\triangle$ : relatively small or partial opinion; -: no opinion.

*EHS officer: environmental health and safety officers, enviro-NGOs: environmental nongovernment organizations. 
ments by stakeholders. Further details are provided below.

\section{1) EHSNIC awareness}

EHSNIC awareness differed across stakeholders. Resident representatives often had direct or indirect experience and knew about EHSNIC in detail as they or their neighbors or family members participated in it. Although enviro-NGOs were often aware of the EHSNIC's background and content in detail, they had not accessed EHSNIC results, except for in its early years. Not only were EHS officers from large companies aware of the EHSNIC's background and content but those companies had also designated employees to specifically monitor its results. Most EHS officers from small companies had either not heard of the EHSNIC or were just aware that it existed. Since local government officials provide administrative support for EHSNIC implementation, most knew of it but only in relation to their administrative work; they were often unaware of the specifics of its content.

"As you mentioned, my company had interest in the EHSNIC. So I was put in charge of monitoring its results" (EHS officer).

"It has been only three months since I took charge of this work, but when I asked my predecessor, he said he had no idea what it did" (local government official).

\section{2) EHSNIC Outcomes}

a) Persistence

Local government officials and EHS officers said that conducting the national-level study for a long time, since 2003, is itself the outcome.

"For me, I think conducting this kind of study itself nationally would be the outcome" (public official).

"I think conducting the study itself is its outcome" (EHS officer).

\section{b) Database establishment}

All stakeholders said that establishing a database from the EHSNIC was the biggest outcome. Local government officials responded that local governments have difficulty building a large-scale database in a stable manner, and the outcome is to be able to construct and use a database at the national level. However, resident representatives raised questions about merely building a database without releasing the data or not taking follow-up actions such as improvement measures based on the results.

"I believe we have conducted this study and built a database on how badly residents' health deteriorated and whether they were contaminated with heavy metals" (EHS officer).
"My city has not yet secured data. It would be good to have this sort of study and determine the factors contributing to residents' health" (local government official).

"They said they will conduct the study longitudinally for 10 years. I am not sure what they do and how they do it and whether there are data or results" (resident representative).

\section{c) Environmental improvement}

Some EHS officers and resident representatives commented that EHSNIC results had direct or indirect effects on environmental control in companies. In particular, the Ministry of Environment rejected a request for constructing a thermal power plant in the Pohang NICA in 2016, and EHS officers and resident representatives believed the EHSNIC provided evidence for this decision.

"When they do the study, it seems that it is shared directly or indirectly with the Ministry of Environment or cities. Once it is shared, whether it is city's air or water quality, it seems to have a direct or indirect effect on companies" (EHS officer).

\section{3) EHSNIC's limitations}

a) No healthcare action taken based on the results

Resident representatives and enviro-NGOs suggested that no proper healthcare actions have been taken based on the EHSNIC's results, even though it has been conducted since 2003. Some residential areas near NICAs lacked basic environmental health services such as waterworks. In some regions, polluting facilities, such as waste treatment plants, airfields, and incinerators, were gathered in addition to NICAs, but there had been almost no healthcare actions using EHSNIC results.

"It has been more than 30 years since the steel mill was built. The country should consider how residents' health worsened or how they were contaminated, but there has been no such approach" (enviro-NGO).

"Our neighborhood now has waterworks. Even though pollution is severe, we have drank underground water" (resident representative).

\section{b) Lack of results release}

Since the second phase of the EHSNIC, its results have been available to participants, but some said they had not received their results. Most enviro-NGOs and resident representatives were interested in the EHSNIC results, but the results had not been made public. Most local government officials and EHS officers also commented that it is necessary to release the results. However, the scope of disclosure varied across stakeholders. 
"I have waited. They said they will conduct the study longitudinally for 10 years. I am not sure what they do and how they do it and whether there are data or results" (enviroNGO).

"We do not have specific data, but they said the death rate from lung disease is overwhelmingly high. They need to make data available to us so that we can think about what to do. But it just puts us in trouble when they only pressure us without releasing the data" (EHS officer).

"I think we should make the data public and make sure everyone knows about the data. I do not think we can hide it, even if we try" (local government official).

\section{c) Survey design not reflecting local characteristics}

Some resident representatives, enviro-NGOs, and local government officials commented that studies do not reflect NICA characteristics. For example, each NICA uses different substances.

"There are too many general studies. If they focus on studies targeting specific regions, they might be able to conduct the studies more efficiently" (enviro-NGO).

\section{d) Validity of the EHSNIC and its results}

Resident representatives, enviro-NGOs, some local government officials, and EHS officers commented that they could not trust the EHSNIC and its results. Resident representatives and enviro-NGOs said they could not trust it because of the EHSNIC's background, a gap between actual exposure and measured exposure, and a discrepancy between results showing little effect on health and on-the-ground reality. Some local government officials said the results cannot be trusted since measurement points are not standardized. EHS officers commented that it is not certain whether subjects were selected to ensure representation, whether the results only examined the effect of NICAs and excluded personal variables (e.g., age, disease, daily life habits), and whether the results can represent the entire NICA.

"Although there was a correlation between exposure to environmental pollution and health in the first epidemiological study conducted in the region (another study, not the EHSNIC), they said they needed an additional study. So, we asked the city to conduct the second study. However, the city decided not to do the second study, and around that time, the NIER was going to conduct the EHSNIC as a cohort study. They were going to examine how things would change from today, so we could not accept it under any circumstances. Afterward, the resident health effect study and the environmental study were performed, but we cannot understand something like this" (resident representative).

"Since there have been no significant results, we are disappointed. What are you going to accomplish by studying it for 20 years? We cannot help but have no trust. So, it seems that we just think the EHSNIC is something the government does" (enviro-NGO).

"Seniors become sick and pass away without knowing why. It is the role of the government to let them know why. But if you look at the government now, it seems to be trying to prove otherwise with the study. So, we do not trust them" (enviro-NGO).

"If you look at the study results, they are quite different from what we experience. Even though the results fall short of the threshold, that is not what we experience" (resident representative).

"There is no difference between people near NICAs and the control group. But they said it is high, so it makes no sense" (local government official).

"Those who can participate in the study during that time are those who do not work or who are old or sick" (EHS officer).

"They said they will examine a thousand people. But those thousand people have different ages and jobs. To what extent do they consider this when they conduct the study?" (EHS officer).

"They have to look at individuals, including personal habits and dietary intake" (local government official).

"Do they consider local characteristics? Region 00 has a higher level of radon, and there are many other things [to consider], such as climate" (EHS officer).

\section{4) EHSNIC continuation}

Most stakeholders said the EHSNIC should be conducted continuously.

"I think it must be conducted. We need the basic data" (resident representative).

\section{5) EHSNIC improvement directions}

a) Reflect NICA specificity

Enviro-NGOs, local government officials, and resident representatives commented that a study tailored to NICAs is needed, considering each NICA uses different substances.

"There are specific things to note in each region. Petrochemical NICAs are all different. Thus, the substances people are exposed to are all different. If you reveal at least some health effect specifically appropriate to the NICA, I believe that would fulfill the study's ultimate purpose" 
(enviro-NGO).

"Since our NICA is petrochemical, it would be good to investigate VOCs more" (enviro-NGO).

"Since we are affected by the atmosphere when it becomes a low-pressure area, it would produce good data if they would divide it more specifically [depending on changing climate conditions]" (local government official).

\section{b) Identify pollutant exposure's correlation with disease}

Resident representatives and enviro-NGOs commented that since the first and second phases had already been completed, a future EHSNIC would need to identify pollutant exposure's correlation with disease.

"Basically, we are asking them to identify a particular symptom caused by a certain substance" (resident representative).

"It is about revealing that residents are suffering due to hazardous substances. They need to reveal it now so we don't have to wait 12 or 13 years" (resident representative).

"They need to confirm it now. Residents are urging them to identify it. What is unfortunate is that people keep getting sick and passing away. Somebody needs to reveal why" (enviro-NGO).

\section{c) Expand survey subjects and ensure representation}

Most resident representatives said the sample size was too small and that all resident representatives should be examined. In addition, resident representatives and local government officials commented that the EHSNIC currently only examines adults but should include children as well. There were comments that it should specifically target children and repeatedly study them in the long run.

"All residents should be studied" (resident representative).

"It should be conducted by age group, including children, elementary school students, and middle school students. Then, you can get a more precise answer" (resident representatives).

"Since it is an epidemiological study, what about studying children from a region over the long term?" (local government official).

\section{d) Include long-term residents}

Some suggested that long-term residents should be included first, considering residential history when selecting subjects. It was noted that residents frequently move in some NICAs; so, those with a short period of residence near such NICAs should be included as subjects.

"I want them to select those who have lived there for a long time" (EHS officer).

"In Region 00, people often move. So, half of the population changes in four or five years" (local government official).

e) Repeated study

Most stakeholders said it was necessary to study subjects repeatedly and identify a causal relation between exposure and disease.

"Even if it is only one individual, it would be better to examine that person for a long time" (local government official).

\section{f) Long-term study}

Some EHS officers and local government officials commented that a long-term study was needed to reduce uncertainty and the margin of error in the results.

"I think we can reduce deviations with long-term monitoring" (EHS officer).

"Data are important, but things can go awry when we disclose them without fully examining them" (local government official).

\section{g) Include health screening and cancer screening}

Most resident representatives said that not including screening in the second phase of the EHSNIC was a problem, and more precise health and cancer screening are needed to identify health effects.

"There are so many cancer patients among residents. Health screenings should be conducted for all residents" (resident representative).

\section{h) Results release}

While most stakeholders wanted results to be released, the scope of the released results varied among them. Resident representatives and enviro-NGOs wanted to share and discuss EHSNIC results and its future plans in briefing meetings. Some EHS officers wanted to selectively disclose results only to companies or did not want to release them at all. Some local government officials also wanted to make them public in phases.

"In the third phase, they should hold a briefing for residents to clearly present the results so we can request things to improve" (enviro-NGO).

"I want them to tell us why they want to do the study before they start" (resident representative).

"If they decide to disclose them later, there are things we need to be careful about. If they make them public without filtering them, the results could be abused or used for 
other purposes. Even though they are not bad data, it is highly likely that they can be interpreted otherwise. So, if they decide to release them, they should consider this as well" (EHS officer).

\section{i) Reliability}

All stakeholders commented that the EHSNIC should be standardized to ensure reliability (e.g., the location of the installed monitoring network). Resident representatives and enviro-NGOs said it is important to select a reliable survey institution and to disclose its selection and investigation process. They also said resident representatives and enviro-NGOs will participate in or support the study.

"[The exposure level was measured as high because] the monitoring network was established incorrectly. It was right next to the stack and was especially affected by cars driving on the road nearby" (EHS officer).

"If there is fine dust, you can see it is very bad with your own eyes. However, when you look at the meter, it is not bad. I cannot understand" (resident representative).

"There are 14 atmosphere measuring points. All of them are located far away, and only one is near the NICA. They should at least make us believe the data are credible" (enviro-NGO).

\section{6) EHSNIC results use}

a) Resident relocation

Resident representatives and enviro-NGOs hoped the results would be used as evidence to relocate residents. In addition to resident representatives and enviro-NGOs, some EHS officers commented that the results are needed to help to relocate residents in residential areas that have become closer to expanding NICAs.

"Pollution is severe and is bad for people. So, we think they would rather relocate us somewhere else" (resident representative).

"They should create a buffer zone between NICAs and residential areas and separate them from each other. Our situation makes us want to relocate" (EHS officer).

\section{b) Separation distance}

NICAs often expand when greenbelt regulations are eased, and resident representatives and local government officials commented that the results should be used to ensure distance between NICAs and residential areas or the green belt.

"First and foremost, we need to create a buffer zone near the old industrial complex" (local government official).

\section{c) Healthcare for residents}

Resident representatives, enviro-NGOs, and some local government officials wanted the EHSNIC results to be used as evidence to provide healthcare support to residents.

"If it is determined that a disease is caused by pollution, it would be good to provide [healthcare] support to residents in NICAs" (resident representative).

"Even though it is the minimum benefits covering healthcare costs, it should help people practically" (enviro-NGO).

\section{d) Local government policy development}

Many local government officials said they would use EHSNIC results as a reference to develop local policies. Many enviroNGOs also said they would use them as a reference to prepare legislative bills, such as the Special Act on the Improvement of Air Quality in the Seoul Metropolitan Area.

"It would be good if the EHSNIC is well conducted and helps to provide good suggestions or measures for residents in terms of health prevention or care" (local government official).

\section{e) Environmental control guidelines for companies}

Many EHS officers from large companies said they would use EHSNIC results for their companies' own environmental control guidelines. EHS officers from small companies said they would need consulting or support for environmental improvement depending on EHSNIC results.

"They can provide guidelines for the company" (EHS officer).

"[Instead of regulations], it would be better to use them in a way where we consult with the companies that cause pollutant exposure" (EHS officer).

\section{Discussion}

The major outcome of EHSNIC was the construction of a database based on continued studies. While some said the EHSNIC reduced civil complaints and directly or indirectly helped improve the environment, many said the decrease in civil complaints was mainly due to the advanced environmental control system [15], changes in production industry type [16], and the use of alternative substances and clean technologies [17]. Hence, that was not mentioned as an EHSNIC's outcome. Comments that the EHSNIC had helped improve the environment were explicitly mentioned in FGIs with EHS officers and resident representatives in some NICAs; thus, it was given as an outcome, even though it was a minority opinion. It was noted that a database built over a long period of time had 
been used as a reference for environmental control and that conducting an epidemiological study itself had had an effect on companies' environmental control. However, arguing that building a database is the EHSNIC's greatest outcome also highlights its biggest limitation-that there have been no proper environmental control measures based on the results. Since EHSNIC's purpose is to study health effects and take proper environmental control actions (under Article 15 of the Environmental Health Act, Epidemiological Investigations of Environment-Related Harm to Health [6, 12]), it should be allowed to take preemptive healthcare actions based on the results [18]. In particular, for regions that do not have basic infrastructure, such as waterworks, where there is a high level of pollutant exposure, including heavy metals, or there are frequent civil complaints due to waste treatment plants or military bases in addition to NICAs, preventive actions should be taken in accordance with Article 4.2 of the Environmental Health Act, even if a scientific correlation is not fully proven.

Since local governments are limited and only provide administrative support for EHSNIC, there is also a need to allow local governments to participate in the studies, use the results, and communicate with residents in terms of using and managing EHSNIC results.

In addition, some resident representatives did not receive their study results. Since the second phase of EHSNIC, results have been disseminated individually; thus, there might be a need for further investigation. It is also important to investigate how to communicate results to residents (e.g., written reports), giving consideration to residents' literacy and how to notify them to ensure they will check the results. While all stakeholders said that, in principle, EHSNIC results should be released, they differed on the extent to which they should be made public. EHSNIC results need to be disclosed in order to take action, and they could be made public in phases depending on the action taken. The lack of trust in EHSNIC means there needs to be sufficient communication with stakeholders regarding its intentions, results, and plans. In addition, it is necessary to standardize items that might affect measured values to enhance the method's validity (e.g., estimating pollutant exposure considering the location of the atmospheric monitoring network) [19].

Regarding EHSNIC continuation, most stakeholders said it should be continued. In terms of the need to examine other NICAs, although EHSNIC currently covers eight NICAs and five regions, it should expand while accommodating each complex's specificity, considering there are more than 1,000 NICAs, including NICAs and regional NICAs [2].

With regard to EHSNIC results use, enviro-NGOs said they would use EHSNIC as a reference to prepare healthcare support for residents or legislative measures, such as the Special Act on the Improvement of Air Quality in Seoul Metropolitan Area [20]. This means an aggregate approach that considers exposure damage to residents is needed, even though pollutant exposure is mostly managed under individual environmental regulations [21].

Even though this study examined 85 relevant stakeholders from eight NICAs and five regions over the course of 18 interview sessions, their comments cannot represent all views on EHSNIC. Nevertheless, we were able to identify the interests and demands of stakeholders in multiple NICAs, including resident representatives and EHS officers. We hope these findings can be used by the EHSNIC in the future.

\section{CONFLICTS OF INTEREST}

The authors have no conflicts of interest associated with the material presented in this paper.

\section{REFERENCES}

1. Kim OS, Eun J, Lee Y-J. Analyzing spatio-temporal trends of deforestation due to industrial complex development in Republic of Korea: a case study of Gyeong-buk and Gyeong-nam Provinces. J Korean Urban Geogr Soc 2016;19(3):103-111.

2. Kim JY, Kang HJ. The arrival of 1,000 industrial complexes and the history of industrial complexes. Issue \& Report 2013;1(1):18.

3. KICOX (Korea Industrial Complex Corporation). Status of the National Statistical Industrial Park. 2017. Contract No. 1. (Korean)

4. Woo K, Park H, Kang T, Kim G, Jeon J, Jang B, et al. Concentration of volatile organic compounds (VOCs) in ambient air and level of residents in industrial area. J Korean Soc Occup Env Hyg 2015;25(1):104114. (Korean)

5. Jeon J-M, Hur D, Kim D-S. Trends of volatile organic compounds in the ambient air of Yeosu industrial complex. J Korean Soc Atmos Env 2003;19(6):663-677. (Korean)

6. NIER (National Institute of Environmental Research). Comprehensive evaluation of the result of five years (2012-2016) monitoring of exposure to environmental pollutants and health effects among residents living near industrial complexes. 2017. [cited Feb 10, 2019] Available from http://webbook.me.go.kr/DLi-File/NIER/06/023/5638949.pdf (Korean)

7. NIER (National Institute of Environmental Research). Calculate emission contribution of major industrial areas and establish management system for source of emissions. 2010. [cited Feb 10, 2019] Available from http://www.prism.go.kr/homepage/entire/retrieveEntireDetail.do;jsessionid=7E6ACE64D3986082031A3E25B2D26768. node02?cond_research_name $=\&$ cond_research_start_date $=\&$ cond research_end_date=\&research_id=1480000-201100008\&pageIndex= 1884\&leftMenuLevel=160 [Korean]

8. Han SJ, Jung YK, Gu DW. Environmental issues and movement in Ul- 
san. Ulsan Development Institute. 2008:207.

9. Kim DH, Lee SK, Chun BY, Lee DH, Hong SC, Jang BK. Illness associated with contamination of drinking water supplies with phenol. J Korean Med Sci 1994;9(3):218-223.

10. Cho S-H, Ju Y-S, Kim K-R, Lee K-K, Hong KS, Eum H-C, et al. Health assessment for glass fiber landfill at Gozan-dong, Inchon. J Prev Med Pub Health 1997;30(1):77-102. (Korean)

11. Joo HS, Lee YS, Lim OJ, Yu JM. A study of the improvement of environmental impact assessment of industrial complexes based on risk assessment of chemical leakage accidents. Sejong, Korea: Korea Environment Institute. 2013;17(254):1-255. (Korean)

12. NIER (National Institute of Environmental Research). The evaluation and improvement of the monitoring of exposure to environmental pollutants and health effects among residents living near industrial complexes. 2011. [cited Feb 10, 2019] Available from http://webbook. me.go.kr/DLi-File/NIER/06/013/5515610.pdf (Korean)

13. Seidman I. Interviewing as qualitative research. 3rd ed. Seoul, Korea: Hakjisa; 2009, p. 240-268. (Korean)

14. Yin RK. Qualitative research from start to finish. Seoul, Korea: Hakjisa; 2013, p. 1-485. (Korean)

15. Lee YS. Enhancing health and social impact assessment in EIA on in dustrial complex. Sejong, Korea: Korea Environmental Institute; 2013. [cited Feb 10, 2019] Available from https://library.kei.re.kr:444/ dmme/img/001/009/002/\%EA\%B8\%B0\%EB\%B3\%B82013_16_\%EC\% 9D\%B4\%EC\%98\%81\%EC\%88\%98.pdf (Korean)

16. Park T, Choi J. A study on the time series classification and characteristics of industrial complex development in Korea. Korea Spat Plan Rev 2011;68(3):99-119. (Korean)

17. Kim HJ, Moon J, Hwang Y, Kwak I. MACT application effect in petrochemical industry to minimize benzene fugitive emission. J Korean Soc Env Eng 2016;38(8):435-443. (Korean)

18. Park J-W. Legislative study on the response and relief to injuries induced by environmental pollution. Env Law Policy 2013;11:79-123.

19. Park JS, Kim DS, Chung HW. Analysis of uncertainty and variability in environmental epidemiology and health risk assessment studies in Korea. Korean J Env Health 2003;29(5):101-9.

20. Kim D, Yoon BM, Choi MA. Proposal for ordinance of atmospheric environment anagement in Gyeonggi-Do. Suwon, Korean: Gyonggi Research Institute; 2017. [cited Feb 10, 2019] Available from http:// www.gri.re.kr/\%EC\%97\%B0\%ЕA\%B5\%AC\%ЕB\%B3\%B4\%ЕA\%B3\%A0 $\%$ EC\%84\%9C/?brno=8242\&prno=5494 (Korea)

21. Kwon TH. Discussion of the equity and efficiency of total pollution control systems. Korean Assoc Public Adm 2008;12:1-13. 